\title{
Nursing Professionals' Perception of Health Care Quality Management
}

\section{Danielle P. Ribeiro}

Federal University of Goiás

\section{Maria A. Barbosa}

Federal University of Goiás

Marcos R. Fernandes

Federal University of Goiás

\section{Ludimila C. Silva}

Federal University of Goiás

Júlio C. Silva

Federal University of Goiás

\section{Edinamar A. Silva}

Federal University of Goiás

Marinésia A. Prado

Federal University of Goiás

Celmo C. Porto

Federal University of Goiás

\section{Maria C. Queiroz}

Federal University of Goiás

Aroldo Vieira Moraes Filho ( $\square$ aroldodemoraes@gmail.com )

Alfredo Nasser University Center

Ana Lúcia Q. Bezerra

Federal University of Goiás

\section{Research Article}

Keywords: Training, Nursing, Care Quality Management, Health Indicators.

Posted Date: August 17th, 2021

DOl: https://doi.org/10.21203/rs.3.rs-800202/v1

License: (c) (1) This work is licensed under a Creative Commons Attribution 4.0 International License. Read Full License 
Version of Record: A version of this preprint was published at Research, Society and Development on November 10th, 2021. See the published version at https://doi.org/10.33448/rsd-v10i14.22330. 


\section{Abstract}

To understand the perception of nurses in quality management of nursing care at a public health institution in Brazil. Qualitative, participation of 18 nurses. Conducted with an interview, open questions with independent variables: characterization of professionals and outcome (perception of quality management, before - 1st phase - and after - 2nd phase - the intervention). Data organized with the help of ATLAS.ti software, Bardin analysis, with the theme "Delivery of value" in the first phase and the theme "Quality indicators focusing on delivering results" in the second phase. The third theme, "Management of care", in 2 phases. Results showed that the perception of nursing managers about quality management varied between the first and second phases. Considering the revelations about scarce knowledge about quality management, we point out the need to carry out training with a health management approach focused on the management of the quality of care.

\section{Introduction}

The conceptual complexity of quality management shows the relevance of the current hospital organization scenario as being one of the most difficult, not only because of the magnanimity and dimension of its mission, but especially because of the risk of fragmentation of care, even though it has a multidisciplinary team with a high degree of autonomy ${ }^{1}$.

Within this context, nursing is essential to achieve an organizational environment strengthened by quality management of the services provided. This is because these components form the largest professional category in the hospital setting; in addition to the ability to effectively motivate and mobilize yourself and others to achieve positive results in nursing practice and in the work environment, being present in more precious and some more tragic moments, according to the essence of the profession, serving humanity, protecting health by developing a leadership focused on delivering care results, active involvement in therapy and commitment to quality care ${ }^{2,3}$.

It is crucial for nurses to understand their role as healthcare managers, since regardless of their hierarchical level in the organization, they exclusively lead the systematization of nursing care and implementation of nursing processes which are configured as management tools for providing management and care articulation; facilitating planning and organization of team actions; and delivering high quality for meeting the patients and nursing team's needs ${ }^{4,5}$.

Under this conception, the qualified nurse professional plays an important role in the articulation between care and management. The leadership praxis and the knowledge of the nurse manager are essential for the performance of their activities, since it is their responsibility to administer care in different areas of the hospital, mapping processes focused on improving the quality of care ${ }^{6,7}$.

This study's objective was to understand the perceptions of nurses on quality care management. 


\section{Methods}

\section{Ethical terms}

The research protocol was approved by the Research Ethics Committee of the Maternal and Child Hospital, under number CEPES/HMI/GO 1,447,390, and the participants signed an Informed Consent Form (ICF). All procedures were performed according to the guidelines of the National Health Council Resolutions, under 466/2012 and 510/2016 legislation ${ }^{8}$.

\section{Procedures}

This qualitative study formed part of an anchor project entitled: Audit process conducted in a large public health institution specializing in maternal and child care in Goiás, a central region of Brazil, during October 2018 to August 2019.

The study used non-probability sampling. It included nurses who had an employment relationship with the institution, and were managing healthcare in the neonatal, pediatric, and maternal ICU, as well as the neonatal semi-ICU; whereas, it excluded those on medical or maternity leave, vacation, or who had been transferred in one of the two phases of data collection.

To define the site of interviews, the institution's nursing manager and care managers of the neonatal, pediatric and maternal ICUs as well as neonatal semi-ICU were first contacted, and thereafter sent individual and nominal invitations, containing the date, time, and site.

To broadly explore the subject using each participant's information, interviews were held in the neonatal ICU's meeting room individually and without interruptions.

The study researcher began the interview by explaining the objectives of the research, which were then read together. Thereafter, questions were asked, and the answers were recorded to maintain data reliability during their transcriptions.

The interlocutions occurred before and after the intervention during October-November 2018 and JulyAugust 2019, respectively, and were referred to as the first and second phases.

The educational intervention occurred after the analysis of the nurses' perceptions about quality management in health in the first phase. It subsidized the determination of thematic axes and guided the elaboration of educational action developed by factoring scientific aspects on a conceptual map (definition, objectives, and types), brainstorming, quality care management, and quality tools. Thereafter, the participants built a conceptual map on quality management problems identified in the institution, followed by brainstorming in groups on strategic ideas to solve the problems highlighted. This activity was developed in a single module, at the institution, according to the work shift of each professional during February and March 2019. 
The instrument used for data collection consisted of seven open questions on perceptions of quality, its management, its positive and negative aspects, and factors hindering quality management ${ }^{9}$.

The independent variables were sex (male/female), middle ages (years lived), place of operation (neonatal / pediatric / maternal / semi-intensive neonatal ICU), formal education (years), specialization (yes/no), and professional performance time (years). The study's outcome was the evaluation of the management of quality of care using the instrument described above.

The data were subjected to content analysis proposed by Bardin ${ }^{10}$, following which, it was organized from significant fragments of texts in the professionals' reports using ATLAS.ti Information Technology Software ${ }^{11}$.

Codification was followed by analysis, interpretation, and the creation of "super families" or categories, with "families" referring to themes, "codes" representing sense nuclei, and "quotations" being significant fragments of the reports from which the sense nuclei were extracted.

\section{Results}

Of the 30 nurses working in the ICUs (maternal, pediatric, and neonatal) and neonatal semi-ICU, 28 (93\%) and $18(64 \%)$ participated in the interview's first and second phases, respectively, whereas 10 (36\%) who did not participate in the second phase were excluded for reasons, such as dismissal, transference, medical and maternity leave, and meeting pre-established criteria. Thus, the final sample of the study included 18 nurses eligible for participating in both phases, whose sociodemographic and professional characterization data are shown in Table 1.

Table 1. Sociodemographic and professional characterization data of the study sample $(n=18)$ 


\begin{tabular}{lllll} 
Variables & A & (SD) & N & \multicolumn{1}{l}{$\%$} \\
\hline Age & \multicolumn{1}{c}{41} & 18 & $100 \%$ \\
\hline Sex & F & 18 & $100 \%$ \\
\cline { 2 - 4 } & M & 0 & $0 \%$ \\
\hline Place of performance & Neonatal ICU & 3 & $17 \%$ \\
\cline { 2 - 4 } & Pediatric ICU & 3 & $17 \%$ \\
\cline { 2 - 4 } & Maternal ICU & 4 & $22 \%$ \\
\cline { 2 - 4 } & Neonatal semi-ICU & 8 & $44 \%$ \\
\hline Formal education (years) & From 3 to 10 years & 15 & $83 \%$ \\
\cline { 2 - 4 } & Over 10 year & 3 & $17 \%$ \\
\hline Specialization & It has & 18 & $100 \%$ \\
\cline { 2 - 4 } & Does not have & 0 & $0 \%$ \\
\hline Professional performance time (years) & From 3 to 10 years & 16 & $89 \%$ \\
\cline { 2 - 4 } & Over 10 year & 2 & $11 \%$
\end{tabular}

$A=$ Average; $S D=$ Standard Deviation; $F=$ Feminine; $N=$ Male; $A=$ Amount

Considering the answers of the objective questions, the nurses were asked to talk about healthcare quality. The theme "delivery of values" emerged from the analysis of the first phase and subsequently two categories emerged from the nuclei of meaning, which showed their concern related to the healthcare quality and its importance during treatment. The first category refers to excellence and error minimization and the second to efficiency and effectiveness without mentioning health indicators, as shown below:

[...] Quality I understand, like giving the patient a better condition [...] (Nurse 01A)

[...] I understand that it optimizes our time and procedures; minimizes errors in the ICU; and provides good care [...] (Nurse 06A).

[...] Quality is a service that you efficiently provide for someone [...] (Nurse 05A).

[...] It is what you do best for your patient, seeking the result he needs [...] (Nurse 08A).

The second phase (post-intervention) showed the empirical emergence of the theme quality indicators in health and focused on the delivery of results. In addition, the importance of the use of quality tools in health, such as: dispersion diagram (category 1 ), process flowchart (category 2), and pareto chart (category 3 ), were discussed in the intervention. 
[...] It will help in the best possible way, with more confidence, by knowing all the processes: Service flow, promptitude, reception of the family, confidence in what one is doing, knowing the binomial, as a whole, within what we can offer (materials, medicines, physical, and quantitative staff structure). And that is it [...] (Nurse 9B).

[...] The processes are well designed and completed. It comprises patient care without harming the patients, exactly the opposite, that the patients leave well and receive the best possible care [...] (Nurse 17B).

Most of the answers in both phases indicated concerns on the importance of quality in healthcare actions. However, the need for indicators to measure healthcare eminently appeared in the second phase, sometimes implicitly and at other times explicitly, showing the importance of measuring the healthcare provided, and the results obtained using some management tools. This resulted in the third theme, which included the following categories: First category: Dispersion diagram, identified in the statements below:

[...]Quality for me is assistance with... According to what the patient needs or what the person expects: quality healthcare, scientific knowledge, acquired through quality indicators, identifying problems that could interfere with quality (Nurse 1B).

[...]Quality? That is what we do best, right? Additionally, if we are prepared to offer what he really needs [...] (Nurse 2B).

[...] The indicators that we present are from these protocols. Do they refer to what is done in healthcare? These indicators really show if quality services are being provided or not. So, what is relevant for me is to really work on these indicators, right? It is through protocols and check lists, that we can really reach a denominator that our work is really going well (Nurse 7B).

Some lines originated, in a somewhat veiled way, the second category: Process flowchart, as described below:

[...] It is all that involves care, both for the patient, the team itself, and the service, which is in accordance with the routine, the standard protocols, with beginning, middle, and end (Nurse 4B).

[...] This management is done by employees who are not from the healthcare area, but by using some tools, they can see, where we can improve, where we go wrong. So, their feedback helps us to provide better quality of care [...] (Nurse 5B)

As shown below, sine qua non conditions listed from the answers of most participants are highlighted, in the first and second phases, about relevant quality of care factors, such as: adequate inputs, technical training, process adjustments, and interdisciplinary work. However, in the second phase, the interviewees assimilated that these punctuality problems caused the greatest impact on the result, from which originated the third category: the Pareto chart, according to the quotes below: 
[...] There is no use in just providing good care down there because if the manager does not do the right thing, if he does not maintain the equipment's quality, or if he does not do his part, then our part decreases too. (Nurse 1B).

[...] It is trying to organize things so as to improve them during the shift, for the patient. Let me see here, in the actions, together with the technical team, materials, equipment, all of this [...] (Nurse 14B).

[...] You must maintain a standard; how can I explain... It is no use having all the materials on one day, and the next day not having even the basics to provide healthcare. We are never sure, we have it today, but tomorrow? It causes a great deal of confusion in everyday life [...] (Nurse 2B).

[...] Team training to use check lists for invasive procedures, systematization of our services, action planning (Nurse 4B).

In both phases, when questioned about the concept of quality management in care, the interviewees' answers pointed to things that resulted in the fourth theme - Care Management, and its categories perception, hierarchy, and empowerment, as described below:

[...] Having mastery of the care provided makes one aware of any situations that may cause problems, which enables preventing and solving problems before they affect or harm patients[...] (Nurse1B).

[...] Because I think some professionals, not all, do not accept it, right?! Sometimes, what I see as quality, the others do not see it in the same way. That is why I think a protocol has to be implemented by the directors, manager. Do you also think so? It is not an "option" for the professional whether to comply or not to comply, so that everyone speaks the same language [...] (Nurse 3B).

[...] I understand like this... if we have protocols approved by the institution and a team duly trained for the application of these protocol procedures, nursing becomes safer, more respected too, with more power for decision making [...] (Nurse 07B).

\section{Discussion}

In the first phase of the study, the reports of nursing managers showed their clear concern about the care provided by them, which was focused on delivering values. ${ }^{10}$ Even though they were concerned about offering quality care; at the same time, specific indicators were not cited to evaluate the quality of this care, nor was it linked to an analysis of the structure and process, which would enable more objective and concrete data to evaluate the care provided ${ }^{12}$.

The constant search for quality improvement, excellence, and error minimization forms part of nursing professionals' daily routine, which is revealed in the first category of this theme. Based on value delivery, nursing professionals are encouraged to have a self-evaluative and reflective attitude on their behavior toward professional challenges. This tends to change paradigms, and possibly develop the profession 
based on care subsidized by efficient and effective practice, resurrected in the second category of the first phase of the study ${ }^{13}$.

Thus, healthcare management through managerial knowledge should be the main axis in the work routine of these professionals. It is essential for the nursing manager to haves knowledge about action planning and organization, clinical governance tools, where the levels of knowledge and application of practices are correlated with efficiency indicators, listed through technical instruments of the work process that underlie decision making and consist of the elaboration of strategies that aim to achieve a defined objective ${ }^{14,15}$.

While in both phases of the study, the participants emphasized the importance of quality of care; in the second phase, the interviewees described that evaluating the quality of care would be essential, recognizing that the indicators during the interventional action served as useful tools to measure nursing care, however, they emphasize that defining parameters to measure quality in health care is a potential problem, since it can be assessed using several parameters ${ }^{16}$. According to Silva ${ }^{17}$, this demonstrates that the interviewees understood the importance of accessing indicators that subsidized the evaluation of structure, process, and results, as well as seeking a panoramic view for the applicability of quality and healthcare processes.

According to the interviewees, care and quality management are inseparable, since both aim at completeness, incorporating healthcare production according to clients diverse and individual needs ${ }^{18}$. Nursing managers pointed out the need for implementing care management through concrete actions, especially training that involves all the hospital's existing initiatives, in a hierarchical manner, within a quality system that is not assigned to any specific person or group, but is the whole institution's responsibility and concern.

Despite obtaining satisfactory results, this study's limitations are its non-probabilistic sample, which did not include all nursing managers, and the fact that it was conducted in a single health institution, limited its generalization capacity. Thus, more studies are necessary to evaluate nursing managers' perception about quality and its management in nursing care, estimating the study's reproducibility, and complementing it with different methodologies to add new strategies for greater integration of the theme.

\section{Conclusion}

There are concerns about healthcare quality. Thus, after the educational intervention, there is a need for the use of quality indicators as essential tools to organize quality management.

Most research participants' answers reveal little knowledge of quality management, thus pointing to the need for training with a health management approach focused on quality management, emphasizing the importance of standards and routines as a path for the standardization of care and continuous quality improvement. This type of an intervention is relevant due to its dexterity in easily diagnosing failures in care processes, rather than in developing and implementing actions with tangible results. 
The use of management tools to evaluate health indicators and other quality management strategies can provide the manager with expertise in action planning, organizing, and developing; in addition to the evaluation of healthcare and management processes in public or private health institutions, based on concepts, principles, and tools aimed at quality and patient safety.

Therefore, the use of quality management strategies should be seen in its entirety, by focusing on the quality of care process as a whole and not only as a single professional's responsibility. Thus, when quality management is institutionalized, all initiatives inherent to this aspect are contemplated, resulting in better quality and organized processes.

\section{Declarations}

\section{Acknowledgments:}

The authors thank all the participants from the Graduate Program in Health Sciences at the School of Medicine of the Federal University of Goiás.

\section{Data availability:}

All data generated or analysed during this study are included in this published article.

\section{Funding:}

This research received no specific grant from any funding agency in the public, commercial, or not-forprofit sectors.

\section{Declaration of Conflicting Interests:}

The Author(s) declare(s) that there is no conflict of interest.

\section{Author contributions}

D.P.R., M.A.B. and A.L.Q.B. conceived and designed the study; D.P.R., L.C.S., M.A.P. and M.C.Q. conducted the experiments; M.R.F., J.C.S., E.A.S. and A.V.M.F. analyzed the data; D.P.R. and C.C.P. wrote the manuscript. All authors read and approved the fnal version.

\section{Competing interests}

The authors declare no competing interests.

\section{References}

1. Aggarwal, A., Aeran, H. \& Rathee, M. Quality management in healthcare: The pivotal desideratum. $J$ Oral Biol Craniofac Res.9, 2, 180-182. DOI: https://doi.org/10.1016/j.jobcr.2018.06.006. (2019). 
2. Govindan, R. \& Sadayappan, A. Nursing Empowerment for Quality Improvement. Int. J. Adv. Nur. Management., 4, 3, 317. DOI: 10.5958/2454-2652.2016.00071.8. (2016).

3. Ventura-Silva, J.M.A., Ribeiro, O.M.P.L., Santos, M.R., Faria, A.C.A., Monteiro, M.A.J. \& Vandresen, L. Organizational planning in the context of a COVID-19 pandemic: implications for nursing management. Journal Health NPEPS. 5, 1, 4626. DOI: http://dx.doi.org/10.30681/252610104626. (2020).

4. Conselho Federal De Enfermagem Cofen. Resolução n. 358/2009. Avalilable in: www.cofen.gov.br/resoluo-cofen-3582009_4384.html. Accessed June 18, 2019. (2009).

5. Bonato, V.L. Gestão de qualidade em saúde: melhorando assistência ao cliente. O Mundo da Saúde. 35, 5:319-331. DOI: 10.15343/0104-7809.20113319331. (2011).

6. Silva, T.A., Solano, R.M.D.C., Siles, J., Freitas, G.R. Professional Identity of Nurse Manager in the Light of the Structural Dialectic Care Model. Aquichan.19, 3, 935. DOI:

http://dx.doi.org/10.5294/aqui.2019.19.3.5. (2019).

7. Nardini, C. Essere Infermiera Case Manager. Recenti Prog Med. 110:372-373. DOI:

10.1701/3197.31752. (2019).

8. BRASIL, Ministério da Saúde Conselho Nacional de Saúde Resolução № 466, de 12 de de- zembro de 2012. DOU n 12 - quinta-feira, 13 de junho de 2013 - Seção 1 - Página 59. Disponível em: <https://bvsms.saude.gov.br/bvs/saudelegis/cns/2013/res0466_12_12_2012.html>. Acesso em: 10 nov.2017.

9. Rabenschlag, L.A., Lima, S.B.S., Eberhardt, T.D., Kessler, M., Soares, R.S.A. \& Camponogara, S. Gestão da Qualidade na Assistência de Enfermagem em Unidade de Clínica cirúrgica. 2015. Rev. Enferm UFSM. 5, 2, 235-246. DOI: http://dx.doi.org/10.5902/2179769215891 (2015).

10. Bardin L. Análise de conteúdo. São Paulo: Edições 70. 2011.

11. Oliveira, P.C., Nakayama, M.K., Torres, M.K.L. \& Nunes, C.S. O Uso do Learning Management System (LMS) por Gestores de Educação a Distância. Rev. Bras. Aprend. Aberta. I: 346. https://doi.org/10.17143/rbaad.v19i1.346. (2019).

12. Karaca, A., Durna, Z. Patient satisfaction with the quality of nursing care. Nurs Open. 6, 2:535-545. DOI: https://doi.org/10.1002/nop2.237. (2019)

13. Yang, C.C. Measuring health indicators and allocating health resources: a DEA-based approach. Health Care Manag Sci.20, 365-378. DOI: https://doi.org/10.1007/s10729-016-9358-2. (2017)

14. Sarchielli, G, et al. Is medical perspective on clinical governance practices associated with clinical units' performance and mortality? A cross-sectional study through a recordlinkage procedure. SAGE Open Med.,4, 1-12, DOI: 10.1177/2050312116660115. (2016) 
15. Soares, M.I., Camelo, S.H.H., Resck, Z.M.R. \& Terra, F.S. Saberes gerenciais do enfermeiro no contexto hospitalar. Rev Bras Enferm [Internet]. 69, 4, 676-83. DOI: http://dx.doi.org/10.1590/00347167.2016690409i. (2016)

16. Khangah, H.A., Jannati, A., \& Imani, A. Assessment of Healthcare Providers' Performance Considering Three Healthcare Quality Indicators: A Review Article. Shiraz E-Med J., 17, 4-5, DOI: 10.17795/semj37522. (2016)

17. Silva, T.O., Vieira, L.M., Lemos, T.S. Gestão hospitalar e gerenciamento em enfermagem à luz da filosofia lean healthcare. Cogitare enferm.24,DOI: http://dx.doi.org/10.5380/ce.v24i0.60003 (2019)

18. Baó, A.C.P., Amestoy, S.C., Moura, G.M.S.S. \& Trindade, L.L. Indicadores de qualidade: ferramentas para o gerenciamento de boas práticas em saúde. Rev Bras Enferm [Internet]., 72, 2, 377-84. https://doi.org/10.1590/0034-7167-2018-0479. (2019) 